Check for updates

Cite this: RSC Adv., 2018, 8, 32719

Received 28th June 2018

Accepted 3rd September 2018

DOI: $10.1039 / \mathrm{c} 8 \mathrm{ra05529g}$

rsc.li/rsc-advances

\section{Tailoring of the chlorine sensing properties of substituted metal phthalocyanines non-covalently anchored on single-walled carbon nanotubes}

\author{
Anshul Kumar Sharma, ${ }^{a}$ Aman Mahajan, (D) *a Subodh Kumar, ${ }^{\text {b }}$ A. K. Debnath ${ }^{c}$ \\ and D. K. Aswal ${ }^{\text {d }}$
}

\begin{abstract}
To investigate how central metal tunes the synergetic interactions between substituted metallo-phthalocyanine and single-walled carbon nanotubes in enhancing the gas sensing properties, a comparative study has been performed by varying the central metal ion in fluorinated metal phthalocyanines and single-walled carbon nanotube hybrid. Hybrids of metal(II)-1,2,3,4,8,9,10,11,15,16,17,18-24,25-hexa-decafluoro-29H,31Hphthalocyanine/single-walled carbon nanotube $\left(\mathrm{F}_{16} \mathrm{MPc} / \mathrm{SWCNTs}-\mathrm{COOH}\right.$, where $\left.\mathrm{M}=\mathrm{Co}, \mathrm{Zn}\right)$ have been synthesized through $\pi-\pi$ stacking interactions using the solution route. Spectroscopic (FT-IR, UV-vis, XPS and Raman), electron microscopic (TEM and FE-SEM) and TGA investigations have confirmed the successful functionalization and interaction of SWCNTs- $\mathrm{COOH}$ with $\mathrm{F}_{16} \mathrm{MPc}$. Parts per billion (ppb) level $\mathrm{Cl}_{2}$-selective chemiresistive gas sensors have been fabricated on glass substrates with precoated gold electrodes by using these hybrids. The responses of various $\mathrm{F}_{16} \mathrm{MPc} / \mathrm{SWCNTs}-\mathrm{COOH}$ sensors have demonstrated the central metal ion-dependence in the sensitivity of $\mathrm{Cl}_{2}$.
\end{abstract}

\section{Introduction}

Chlorine $\left(\mathrm{Cl}_{2}\right)$ is commonly used in water purification, pharmaceuticals, textiles, plastics, agrochemicals and household cleaning products etc. Despite being a toxic gas with an occupational exposure limit (OEL) of $500 \mathrm{ppb}$ for a time-weighted average of over eight hours, it can cause distress in the respiratory system and severely affect the environment and mankind. ${ }^{1,2}$ The very precise monitoring of $\mathrm{Cl}_{2}$ at the parts per billion ( $\mathrm{ppb}$ ) or parts per trillion (ppt) level has led to the development of economical, flexible, compact and low power consuming sensors. Different materials like metal oxides, ${ }^{3-5}$ organic semiconductors ${ }^{6,7}$ and carbon-based nanomaterials ${ }^{8,9}$ have been widely explored for the fabrication of gas sensors. Metal oxide-based (particularly $\mathrm{SnO}_{2}, \mathrm{ZnO}, \mathrm{WO}_{3}, \mathrm{TiO}_{2}, \mathrm{~V}_{2} \mathrm{O}_{5}$ ) chemiresistive gas sensors have been investigated for the detection of various toxic gases. ${ }^{10,11}$ In organic semiconductors, polycyclic aromatic hydrocarbons, phthalocyanines, porphyrin derivatives and polymers have been used as excellent sensing materials for the detection of various harmful gases. ${ }^{12,13}$ Carbon-based nanomaterials, fullerenes, graphene, and carbon nanotubes (CNTs), have been demonstrated as promising gas sensing materials. ${ }^{14,15}$ However, the gas sensing characteristics

${ }^{a}$ Material Science Laboratory, Department of Physics, Guru Nanak Dev University, Amritsar, 143005, India. E-mail: aman.phy@gndu.ac.in

${ }^{b}$ Department of Chemistry, Guru Nanak Dev University, Amritsar, 143005, India

'Technical Physics Division, Bhabha Atomic Research Centre, Mumbai, 400085, India ${ }^{d}$ CSIR-National Physical Laboratory, New Delhi, 110012, India of CNT hybrids with noble metal nanoparticles, ${ }^{16}$ metal oxides ${ }^{17}$ and organic semiconductors ${ }^{18,19}$ are better in comparison to pristine CNTs due to the better charge transfer between the hybrid and gas analytes.

Among the organic semiconductors, metallophthalocyanines (MPcs) are attractive choices for the noncovalent functionalization of CNTs because of the synergic interaction of MPcs with CNTs due to $\pi-\pi$ interactions..$^{20,21}$ MPcs have emerged as outstanding sensing materials in highly selective, sensitive and reversible chemiresistive gas sensors to detect various toxic gases due to their conjugated macrocyclic units. ${ }^{22,23}$ We have previously reported the nanostructured growth of substituted MPcs for ppb level $\mathrm{Cl}_{2}$ gas sensors with detection limits as low as 5 ppb..$^{24,25}$ Monllau et al. ${ }^{26}$ reported highly sensitive multiwalled carbon nanotubes and epoxy resinbased amperometric sensors for the detection of free chlorine in water, at concentrations as low as $20 \mu \mathrm{g} \mathrm{L}^{-1}$. Wang et al. ${ }^{27}$ fabricated lead phthalocyanine modified CNTs with enhanced $\mathrm{NH}_{3}$ sensing performance as compared to pristine CNTs. Liang et $a .^{20}$ developed substituted metal(II) phthalocyanine/multiwalled carbon nanotube hybrid (TFPMPc/MWCNT, $\mathrm{M}=\mathrm{Co}$, $\mathrm{Zn}, \mathrm{Cu}, \mathrm{Pb}, \mathrm{Pd}$, and $\mathrm{Ni}$ ) sensors where the central metal atoms play an important role in the high sensitivity and selectivity of the sensor towards $\mathrm{NH}_{3}$. The response of the TFPMPc/MWCNT hybrid sensor to ammonia vapour is in the order of $\mathrm{Co}>\mathrm{Zn}>\mathrm{Cu}$ $>\mathrm{Pb}>\mathrm{Pd} \sim \mathrm{Ni}$, which has been attributed to the binding energies of the MPc- $\mathrm{NH}_{3}$ system. ${ }^{20}$ Recently, we fabricated $\mathrm{Cl}_{2}$ sensors using hybrids of carboxylic functionalized multi-walled carbon nanotubes with hexadecafluorinated metal 
phthalocyanines, $\left(\mathrm{F}_{16} \mathrm{MPc}, \mathrm{M}=\mathrm{Cu}, \mathrm{Zn}, \mathrm{Co}\right)$ and the response of the sensors to $\mathrm{Cl}_{2}$ lies in the order of $\mathrm{Co}>\mathrm{Cu}>\mathrm{Zn} .^{28-30}$ Kaya et al. ${ }^{31}$ have shown that the response of the sensor to ammonia vapor in the concentration range $20-50 \mathrm{ppm}$ is of the order CuPc-py $>$ CoPc-py $>\mathrm{H}_{2} \mathrm{Pc}$-py. It is worth mentioning that singlewalled carbon nanotubes (SWCNTs) have certain superior features compared to the MWCNTs due to the comparatively smaller size, stronger inter-tube attraction, and larger specific area of SWCNTs that will enhance the gas adsorption capability and will enhance the gas sensing parameters of the sensor. In our previous study, we have shown that the $\mathrm{F}_{16} \mathrm{CuPc} / \mathrm{SWCNTs}-$ $\mathrm{COOH}$ hybrid sensor seems to be a significantly better candidate for gas sensing applications in comparison to the $\mathrm{F}_{16} \mathrm{CuPc} /$ MWCNTs-COOH hybrid sensor. ${ }^{28}$

Taking these facts into consideration, in order to tune the $\mathrm{Cl}_{2}$ sensing properties of the MPc/CNTs hybrid and to verify the effect of the central metal in the phthalocyanine molecule, we have synthesized hybrids of SWCNTs-COOH with metal(II) 1,2,3,4,8,9,10,11,15,16,17,18-24,25-hexadecafluoro-29H,31 $\mathrm{H}$ phthalocyanine $\left(\mathrm{F}_{16} \mathrm{MPcs}\right.$, where $\left.\mathrm{M}=\mathrm{Co}, \mathrm{Zn}\right){ }^{32-34}$

Fig. 1 shows the schematic diagram of the $\mathrm{F}_{16} \mathrm{MPcs}$ molecules used in this work. Further, due to molecular functionalization, the molecular orbitals come closer to the Fermi level, leading to an increase in the ionization potential and electron affinity, which result in the preferred acceptor behaviour. ${ }^{34}$

\section{Experimental}

The SWCNTs and $\mathrm{F}_{16} \mathrm{MPcs}$ (where $\mathrm{M}=\mathrm{Co}$, Zn) samples were commercially procured from Sigma-Aldrich. The acidification of SWCNTs consisting of the acidic group $(-\mathrm{COOH})$ was performed through the established multi-step acid treatment procedures. ${ }^{35}$ It is worth mentioning that the carboxyl group imparts negative charges and results in the long-term stability of the CNTs dispersion. ${ }^{35,36}$ Varying amounts of $\mathrm{F}_{16} \mathrm{MPcs}(0.1$ to $0.5 \mathrm{wt} \%$ )

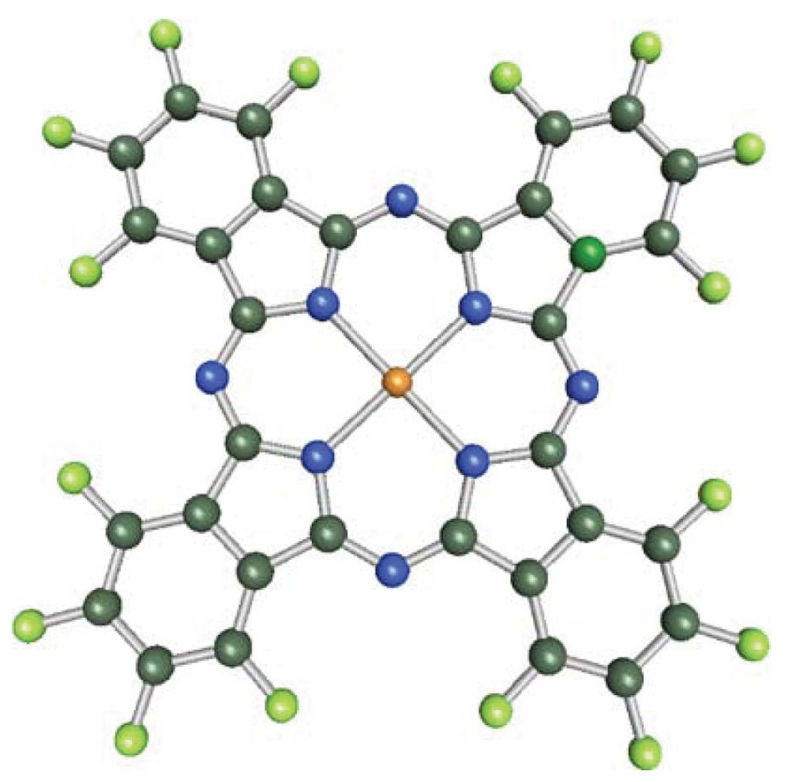

Fig. 1 Schematic diagram of the $F_{16}$ MPcs molecules used in the present study. were dissolved in $5 \mathrm{~mL}$ of dimethylformamide (DMF), and subsequently subjected to stirring to give the $\mathrm{F}_{16} \mathrm{MPcs} / \mathrm{DMF}$ solution. The above solution was then successively and cautiously added dropwise to the SWCNTs-COOH (30 mg) suspensions in DMF and then sonicated at room temperature $\left(25^{\circ} \mathrm{C}\right.$ ) for $3 \mathrm{~h}$ and stirred in the dark for $6 \mathrm{~h}$ at $100{ }^{\circ} \mathrm{C}$. After stirring and filtration through a PTEF filter $(0.22 \mu \mathrm{m}$, Millipore), the product was washed thoroughly with DMF to eradicate the excess $\mathrm{F}_{16} \mathrm{MPcs}$ derivative, followed by washing with ethanol numerous times, then finally drying to acquire $\mathrm{F}_{16} \mathrm{CoPc} /$ SWCNTs-COOH $\left(\mathrm{S}_{1}\right)$ and $\mathrm{F}_{16} \mathrm{ZnPc} / \mathrm{SWCNTs-COOH}\left(\mathrm{S}_{2}\right)$ hybrids.

Raman spectra were obtained using a Renishaw inVia microRaman spectrometer. Fourier transform infrared (FT-IR) and ultraviolet-visible (UV-vis) spectra of $S_{1}$ and $S_{2}$ hybrids were obtained on a Perkin Elmer Frontier FT-IR spectrometer and UV-2450PC (Shimadzu, Japan) spectrophotometer, respectively. The morphologies of $S_{1}$ and $S_{2}$ hybrids were determined by field emission scanning electron microscopy (FE-SEM, Carl Zeiss, supra 55) and transmission electron microscopy (Jeol, TEM2100). Thermogravimetric analysis (TGA) was performed using a thermogravimetric analyzer (Hitachi STA 7200) under a nitrogen atmosphere from 40 to $900{ }^{\circ} \mathrm{C}$ at a scan rate of $10{ }^{\circ} \mathrm{C} \min ^{-1}$. X-ray photoelectron spectroscopy (XPS) was conducted using a $\mathrm{Mg} \mathrm{K}_{\alpha}$ X-ray beam as the excitation source (1253.6 eV) and a MAC2 electron analyzer system attached to an MBE machine (EVA-32 Riber, France). The binding energy scale was calibrated to the $\mathrm{Au} 4 \mathrm{f}_{7 / 2}$ line of $84.0 \mathrm{eV}$.

The gas sensing studies were carried out using a homemade gas handling test chamber $(1000 \mathrm{~mL})$ containing a sample holder geometry as shown in Fig. 2. To prepare gas sensors of $\mathrm{S}_{1}$ and $\mathrm{S}_{2}$ hybrids, $2 \mathrm{mg}$ of the as-prepared $\mathrm{F}_{16} \mathrm{MPcs} / \mathrm{SWCNTs}$ hybrids were dispersed in $1 \mathrm{~mL}$ of DMF and then multiple sensors with effective area of $3 \mathrm{~mm} \times 1 \mathrm{~mm}$ were fabricated by drop casting $30 \mu \mathrm{L}$ of hybrid solution onto a glass substrate with two precoated gold electrodes $(3 \mathrm{~mm} \times 3 \mathrm{~mm}$ at a spacing of 1 $\mathrm{mm})$. Silver wires were attached to the gold electrodes using silver paste. Sensor resistance was recorded continuously by applying a constant bias of $3 \mathrm{~V}$ during both dosing and purging cycles as a function of time, using a computer interfaced Keithley electrometer 6517A. The desired concentrations of $\left(\mathrm{NO}_{2}, \mathrm{NO}, \mathrm{Cl}_{2}, \mathrm{H}_{2} \mathrm{~S}, \mathrm{C}_{2} \mathrm{H}_{5} \mathrm{OH}, \mathrm{CO}\right.$ and $\left.\mathrm{NH}_{3}\right)$ gases in the test chamber were achieved by injecting a known quantity of gas using a micro-syringe; once steady-state was achieved after exposure, sensor resistance was recovered by opening the lid of the test chamber.

The response of the gas sensor was calculated using eqn (1):

$$
S(\%)=\left|\left(R_{\mathrm{a}}-R_{\mathrm{g}}\right) / R_{\mathrm{a}}\right| \times 100
$$

where $R_{\mathrm{a}}$ and $R_{\mathrm{g}}$ represent the sensor resistance in air and gas environments, respectively. The response time is defined as the time needed for the sensor resistance to reach $90 \%$ of its final value after the gas is introduced into the test chamber, and recovery time is defined as the time required for the sensor resistance to regain $90 \%$ of its original value after the purging out of the gas. XPS studies of exposed samples were conducted by the ex situ exposure of gases to the samples in the gas sensing 


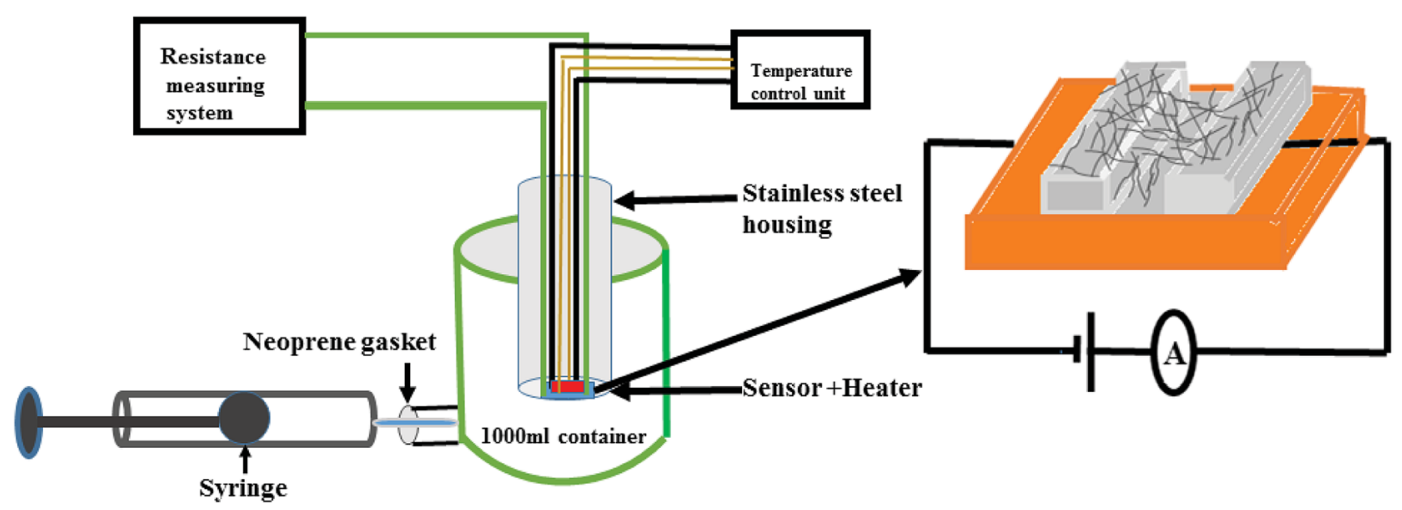

Fig. 2 The gas sensing set-up used in the present study.

set up (Fig. 2) and transferring them to the XPS analysis chamber. The saturated aqueous solutions of $\mathrm{LiCl}, \mathrm{MgCl}_{2}$, $\mathrm{K}_{2} \mathrm{CO}_{3}, \mathrm{NaBr}, \mathrm{KI}, \mathrm{NaCl}, \mathrm{KCl}$ and $\mathrm{K}_{2} \mathrm{So}_{4}$ at an ambient temperature of $25{ }^{\circ} \mathrm{C}$ were used for maintaining homogeneous and stable environments with relative humidities of nearly $11.5 \%$, $32.6 \%, 43.4 \%, 57.3 \%, 68.4 \%, 75.7 \%, 84.5 \%$ and 97.1 respectively. ${ }^{37}$ A hygrometer (Keithley $6517 \mathrm{~A}$ ) was used to independently monitor the relative humidity $(\mathrm{RH})$ levels. Impedance spectroscopy studies of the $S_{1}$ and $S_{2}$ hybrids were carried out using a frequency response analyser (FRA) attached with a potentiostat (Autolab) in the frequency range of $10 \mathrm{~Hz}$ to 1 MHz. In accordance with the sensing study, $0.3 \mathrm{wt} \%$ of $\mathrm{S}_{1}$ and $\mathrm{S}_{2}$ hybrid sensors were chosen for further study.

\section{Results and discussion}

\subsection{Material characterization of the $\mathrm{F}_{16} \mathrm{MPc} / \mathrm{SWCNTs}-\mathrm{COOH}$ hybrid}

In order to explore the interactions between phthalocyanine molecules and SWCNTs-COOH, Raman and FTIR spectroscopic measurements of all the samples were conducted. The Raman spectra (Fig. 3) of SWCNTs-COOH contain the characteristic Gband due to the bond stretching of $\mathrm{sp}^{2}$ atoms at around $1593 \mathrm{~cm}^{-1}$ and the $\mathrm{D}$ band at around $1360 \mathrm{~cm}^{-1}$ due to the breathing mode of $\mathrm{sp}^{2}$ atoms. ${ }^{38,39}$ Moreover, a characteristic peak at $164 \mathrm{~cm}^{-1}$ is for the radial breathing mode (RBM) of SWCNTs-COOH, which signifies the distribution of diameters in the SWCNTs-COOH sample. ${ }^{40}$ The peaks at $143,176,208$, $283,470,513,587,680,738$ and $965 \mathrm{~cm}^{-1}$ in $\mathrm{F}_{16} \mathrm{CoPc}$ and peaks at $118,177,200,281,469,586,727,811$ and $954 \mathrm{~cm}^{-1}$ in $\mathrm{F}_{16} \mathrm{ZnPc}$ are due to the vibrations of isoindole moieties. ${ }^{41}$ The characteristic peaks between 1200 and $1600 \mathrm{~cm}^{-1}$ are due to pyrrole groups. Moreover, bands at 1544 and $1509 \mathrm{~cm}^{-1}$ correspond to cobalt and zinc ions, in agreement with earlier studies. ${ }^{41-43}$ It is worth noting that a combination of peaks of both the $\mathrm{F}_{16} \mathrm{MPcs}$ and SWCNTs-COOH were found in the Raman spectra of $S_{1}$ and $S_{2}$ hybrids. Moreover, D and $G$ bands were found to be marginally broadened due to the superimposition with $\mathrm{F}_{16} \mathrm{MPc}$ peaks. Fig. $3(\mathrm{~b})$ shows enlarged parts of the spectra from 100 to $1300 \mathrm{~cm}^{-1}$, in which there is a change in the peak position and intensity of the characteristic Raman peak of the phthalocyanine macrocycle by interaction with SWCNTs-
$\mathrm{COOH}$. The relative intensity ratio $\left(I_{\mathrm{D}} / I_{\mathrm{G}}\right)$ was determined to be $0.3,0.19$ and 0.24 for SWCNTs-COOH, $\mathrm{S}_{1}$ and $\mathrm{S}_{2}$ samples, respectively. ${ }^{28,40}$ A small variation in $I_{\mathrm{D}} / I_{\mathrm{G}}$ demonstrated that $\mathrm{F}_{16} \mathrm{MPc}$ molecules are non-covalently attached to the surface of SWCNTs-COOH. ${ }^{39,40}$ Nevertheless, $\pi-\pi$ stacking interactions between SWCNTs-COOH and $\mathrm{F}_{16} \mathrm{MPcs}$ aromatic rings resulted in the shift of RBM towards a higher frequency. ${ }^{44,45}$ The higher


Fig. 3 Raman spectra of (a) SWCNTs- $\mathrm{COOH}, \mathrm{F}_{16} \mathrm{CoPc}, \mathrm{S}_{1}, \mathrm{~F}_{16} \mathrm{ZnPc}$ and $\mathrm{S}_{2}$ hybrids, and (b) SWCNTs-COOH, $\mathrm{S}_{1}$ and $\mathrm{S}_{2}$ hybrids in the $30-$ $1300 \mathrm{~cm}^{-1}$ range (magnified view). 
frequency shift in the $S_{1}$ hybrid as compared to the $S_{2}$ hybrid indicates that the adsorption of $\mathrm{F}_{16} \mathrm{CoPc}$ induces a more significant shift in comparison to $\mathrm{F}_{16} \mathrm{ZnPc}$, due to the enhanced $\mathrm{F}_{16} \mathrm{CoPc}$ molecule-SWCNT-COOH interaction. ${ }^{44}$

FTIR spectra (Fig. 4) of SWCNTs-COOH show the $\mathrm{C}-\mathrm{O}$ stretching vibration peak at $1021 \mathrm{~cm}^{-1}$, the $\mathrm{O}-\mathrm{H}$ stretching vibration peak at $3440 \mathrm{~cm}^{-1}$ due to the carboxylic group ${ }^{36}$ and a peak at $1637 \mathrm{~cm}^{-1}$ due to the $\mathrm{C}=\mathrm{C}$ stretching vibration. ${ }^{36}$ The peaks at 2855 and $2921 \mathrm{~cm}^{-1}$ correspond to asymmetric and symmetric $\mathrm{CH}_{2}$ stretching vibrations. ${ }^{46}$ The observed IR peaks at $498,605,754,845,966,1158 \mathrm{~cm}^{-1}$ for the $\mathrm{F}_{16} \mathrm{CoPc}$ sample and at $497,600,653,750,834,932,957,1072,1143 \mathrm{~cm}^{-1}$ in the $\mathrm{F}_{16} \mathrm{ZnPc}$ sample are due to the hexadecafluoro substituents. The presence of other peaks at 1283, 1325, 1469, 1496, 1529, 1623, 1737, $2925 \mathrm{~cm}^{-1}$ for $\mathrm{F}_{16} \mathrm{CoPc}$ and at 1261, 1315, 1489, 1522, 1615, $2920 \mathrm{~cm}^{-1}$ for $\mathrm{F}_{16} \mathrm{ZnPc}$ are due to aliphatic $\mathrm{C}-\mathrm{H}$ vibrations. ${ }^{20}$ The peaks appearing in $\mathrm{F}_{16} \mathrm{CoPc}$ and SWCNTs-COOH can be found in the $S_{1}$ hybrid at $604,842,965,1156,1283,1325,1385,1467,1495$, 1529, 1622 and $2915 \mathrm{~cm}^{-1} \cdot{ }^{47}$ Similarly, peaks appearing in $\mathrm{F}_{16} \mathrm{ZnPc}$ and SWCNTs-COOH are observed in the $\mathrm{S}_{2}$ hybrid at 593, 651, 748, 832, 957, 1070, 1141, 1385, 1483, 1520, 1615 and $2912 \mathrm{~cm}^{-1} .^{47}$ It is worth mentioning that the peak appearing at $1385 \mathrm{~cm}^{-1}$ in both the $S_{1}$ and $S_{2}$ hybrids is due to the $\mathrm{C}-\mathrm{N}-\mathrm{C}$ vibration, ${ }^{48}$ which confirms the interaction between phthalocyanine and CNTs. The characteristic peaks of the phthalocyanine molecule in the IR spectra of $S_{1}$ and $S_{2}$ hybrids are found to be slightly red shifted in wavenumber in comparison to their individual peaks. Nevertheless, a higher shift in wavenumber in the $S_{1}$ hybrid in comparison to $S_{2}$ reveals that adsorption of $F_{16} \mathrm{CoPc}$ induces a more significant shift due to the enhanced electron delocalization via $\pi-\pi$ stacking interactions between the $\mathrm{F}_{16} \mathrm{CoPc}$ molecule and SWCNT-COOH, which is concomitant with Raman spectroscopic studies. ${ }^{49}$

Fig. 5 depicts the UV-vis absorption spectra of SWCNTs$\mathrm{COOH}, \mathrm{F}_{16} \mathrm{MPcs}, \mathrm{S}_{1}$ and $\mathrm{S}_{2}$ hybrids. The UV-vis absorption spectrum of SWCNTs-COOH was observed to be featureless ${ }^{50}$ and the spectra of $\mathrm{F}_{16} \mathrm{MPcs}$ exhibit two strong absorption bands, one broad B band in the wavelength range $305-371 \mathrm{~nm}$

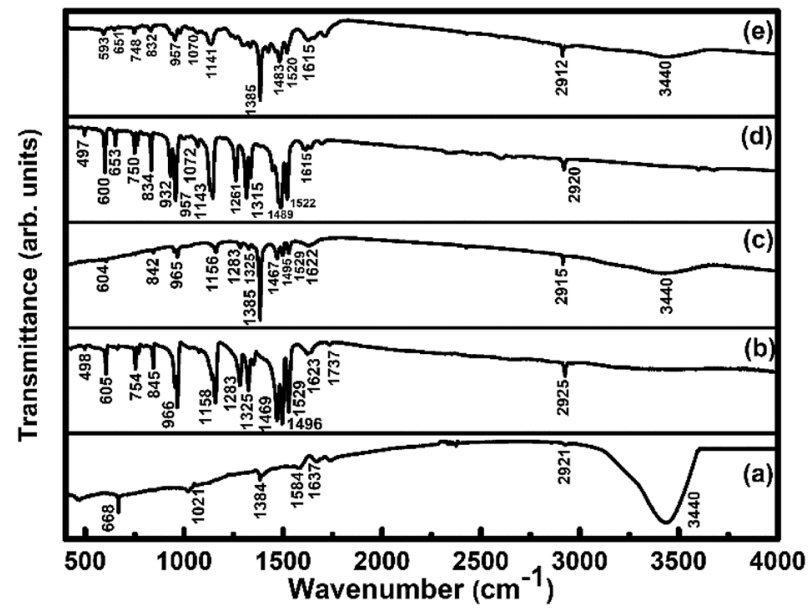

Fig. 4 FTIR spectra of (a) SWCNTs-COOH; (b) $\mathrm{F}_{16} \mathrm{CoPc}$; (c) $\mathrm{S}_{1}$; (d) $\mathrm{F}_{16} \mathrm{ZnPc}$ and (e) $\mathrm{S}_{2}$ hybrid.

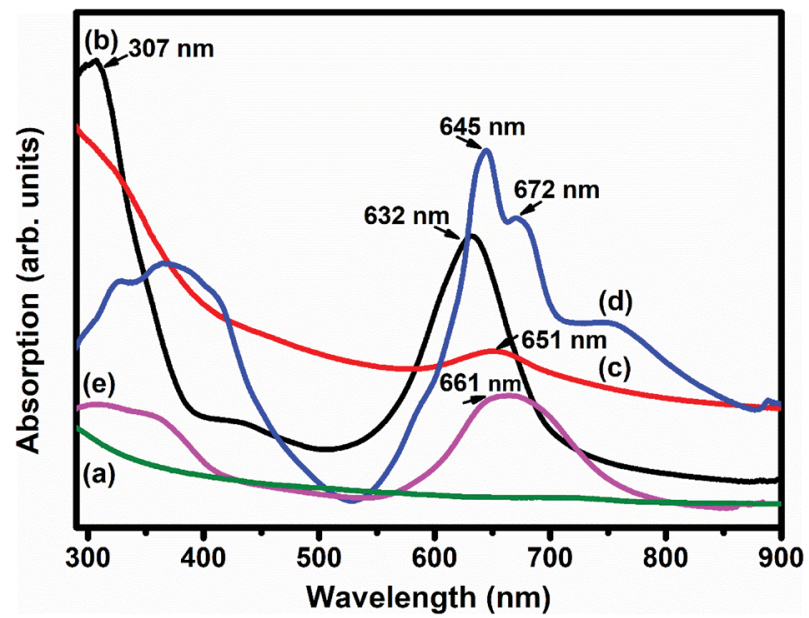

Fig. 5 UV-vis absorption spectra of (a) SWCNTs-COOH; (b) $\mathrm{F}_{16} \mathrm{CoPC}$; (c) $\mathrm{S}_{1}$; (d) $\mathrm{F}_{16} \mathrm{ZnPc}$ and (e) the $\mathrm{S}_{2}$ hybrid.

due to the electronic transitions from the HOMO $\mathrm{a}_{2} \mathrm{u}$ to the LUMO $e_{g}$ level and the $\mathrm{Q}$ band in the visible range at 632$672 \mathrm{~nm}$ is because of the electronic transitions from the HOMO $\mathrm{a}_{1} \mathrm{u}$ level to the LUMO $\mathrm{e}_{\mathrm{g}}$ level..$^{51}$ However, in the case of $\mathrm{S}_{1}$ and $\mathrm{S}_{2}$ hybrids, the Q-band was found to be comparatively broadened with a decrease in absorption in the dispersions containing $\mathrm{F}_{16} \mathrm{MPc} / \mathrm{SWCNTs}-\mathrm{COOH}$ and their maxima were red-shifted by 19 and $16 \mathrm{~nm}$, respectively, as compared to that of the individual $\mathrm{F}_{16} \mathrm{MPc}$ spectrum. It is worth mentioning that the expanded macrocyclic conjugated structure of $\mathrm{F}_{16} \mathrm{MPc}$ and the reduced energy difference between the HOMO and the LUMO facilitates charge transfer between $\mathrm{F}_{16} \mathrm{MPc}$ and SWCNTsCOOH. In addition, the higher red-shift in the $S_{1}$ hybrid as compared to $S_{2}$ confirms the significant $\pi-\pi$ interaction and the charge transfer between $\mathrm{F}_{16} \mathrm{CoPc}$ and SWCNTs-COOH. ${ }^{40}$

TEM (Fig. 6(a and b)) images of $S_{1}$ and $S_{2}$ hybrids demonstrate the exohedral anchoring of phthalocyanine molecules on the walls of SWCNTs-COOH with a mean diameter of about 36 and $29 \mathrm{~nm}$ in comparison to SWCNTs-COOH (inset view) with diameter of about $10 \mathrm{~nm}$. Additionally, scanning electron microscopy images (Fig. 6 (c and d)) of $S_{1}$ and $S_{2}$ hybrids also highlight that phthalocyanine molecules are anchored on the surface of the SWCNTs-COOH matrix, making a thicker SWCNTs-COOH surface in contrast to individual SWCNTs$\mathrm{COOH}$. The weight loss as a function of temperature for SWCNTs-COOH, $\mathrm{F}_{16} \mathrm{ZnPc}, \mathrm{F}_{16} \mathrm{CoPc}, \mathrm{S}_{1}$ and $\mathrm{S}_{2}$ hybrid materials has been investigated using TGA plots (Fig. 7)).

A loss of weight of about $54.60 \%$ and $49.05 \%$ up to $900{ }^{\circ} \mathrm{C}$ was observed for $\mathrm{F}_{16} \mathrm{ZnPc}$ and $\mathrm{F}_{16} \mathrm{CoPc}$ (Fig. 7(a and b)), comprised of major weight losses in steps from 200 to $330{ }^{\circ} \mathrm{C}$ and 366 to $604{ }^{\circ} \mathrm{C}$ due to the desorption of adsorbed water and the decomposition of $\mathrm{F}_{16} \mathrm{MPc}$, respectively. ${ }^{45,52}$ TGA plots of SWCNTs-COOH (Fig. 7(e)) exhibited a weight loss of about $4.21 \%$ due to the destruction of the residual carbon and decarboxylation of oxidized species. ${ }^{40}$ In contrast, $\mathrm{S}_{1}$ and $\mathrm{S}_{2}$ (Fig. 7(c and d) had weight losses of $21.83 \%$ and $22.79 \%$, respectively, on heating the hybrid to $900{ }^{\circ} \mathrm{C}$, corresponding to the decomposition of the $\mathrm{F}_{16} \mathrm{MPc}$ on the SWCNTs-COOH 



Fig. 6 (a and b) TEM images (insets show the TEM images of SWCNTs-COOH) and (c and d) SEM images of the $\mathrm{S}_{1}$ and $\mathrm{S}_{2}$ hybrids.

surface. ${ }^{45}$ The amount of $\mathrm{F}_{16} \mathrm{MPc}$ molecules adsorbed on the SWCNTs-COOH was calculated using the ratio of the difference in weight loss between SWCNTs- $\mathrm{COOH}$ and the $\mathrm{F}_{16} \mathrm{MPc} /$ SWCNTs-COOH hybrid to the weight loss for $\mathrm{F}_{16} \mathrm{MPc}$ and was found to be $35.92 \%$ and $34.02 \%$ for the $\mathrm{S}_{1}$ and $\mathrm{S}_{2}$ hybrids, respectively.

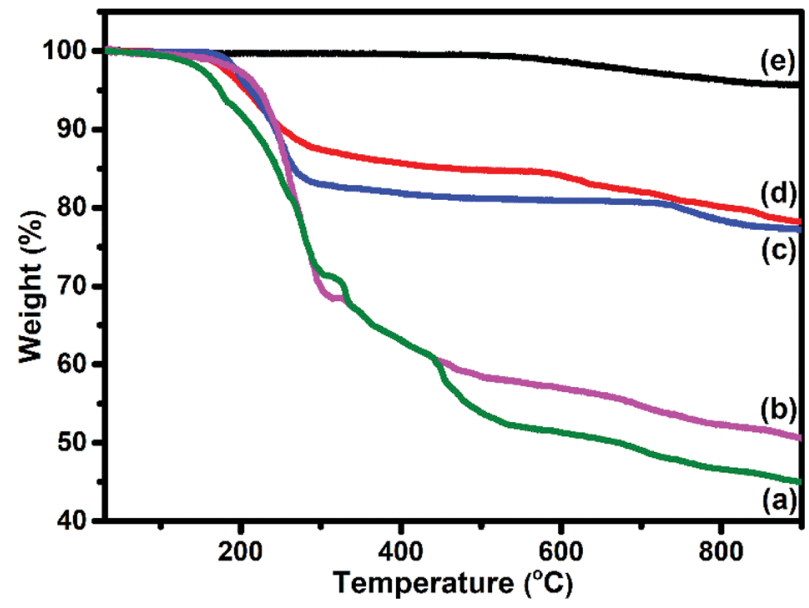

Fig. 7 TGA curves of (a) $F_{16} Z n P C$, (b) $F_{16} \operatorname{CoPC}$, (c) $S_{2}$ (d) $S_{1}$ hybrid and (e) SWCNTs-COOH.

\subsection{Gas sensing measurements}

To demonstrate the gas sensing properties of prepared $\mathrm{S}_{1}$ and $\mathrm{S}_{2}$ hybrid sensors, we recorded the response curves (change in resistance of the film as a function of time) of the sensors to $500 \mathrm{ppb}$ of different test gases at room temperature $\left(25^{\circ} \mathrm{C}\right)$. From the selectivity histogram (Fig. 8), it can be seen that for the tested gases at room temperature, $0.3 \mathrm{wt} \%$ of $\mathrm{S}_{1}$ and $\mathrm{S}_{2}$ hybrid sensors exhibited the best response towards $\mathrm{Cl}_{2}$ among all the prepared sensors, with sensitivity values of $\sim 40 \%$ and $30 \%$, respectively, in comparison to the pristine SWCNTs sensor with a sensitivity value of $\sim 1 \%{ }^{28}$ This indicates that the $\mathrm{F}_{16} \mathrm{MPcs}$ molecule enhances the sensor response because of the synergic interaction of MPcs with CNTs due to $\pi-\pi$ interactions. As such, $0.3 \mathrm{wt} \%$ of $S_{1}$ and $S_{2}$ hybrid sensors was chosen for further sensing studies. The sensitivity values for all other tested gases were $<4 \%$. Moreover, at room temperature, the sensors showed irreversible behaviour, as they did not recover to the baseline resistance even after a long interval of time. It was observed that heating improves the recovery characteristics of the sensors; the operating temperature was optimized in order to make the sensors reversible. Here, both sensors $\mathrm{S}_{1}$ and $\mathrm{S}_{2}$ were exposed to $500 \mathrm{ppb}$ of $\mathrm{Cl}_{2}$ at different operating temperatures ranging from $25{ }^{\circ} \mathrm{C}$ to $200{ }^{\circ} \mathrm{C}$. A plot of sensor response for $500 \mathrm{ppb}$ of $\mathrm{Cl}_{2}$ as a function of temperature is shown in Fig. 9(a). The response for 



Fig. 8 (a and b) Selectivity histogram of $\mathrm{S}_{1}$ and $\mathrm{S}_{2}$ sensors for 500 ppb of $\mathrm{NO}_{2}, \mathrm{NO}, \mathrm{Cl}_{2}, \mathrm{C}_{2} \mathrm{H}_{5} \mathrm{OH}, \mathrm{H}_{2} \mathrm{~S}, \mathrm{NH}_{3}$ and $\mathrm{CO}$ at room temperature.

$\mathrm{Cl}_{2}$ was rapidly enhanced with increasing temperature and the maximum responses of $\sim 59 \%$ and $46 \%$ were obtained for sensors $S_{1}$ and $S_{2}$, respectively, at $150{ }^{\circ} \mathrm{C}$. Furthermore, the response of the sensors decreases beyond $150{ }^{\circ} \mathrm{C}$, due to desorption of $\mathrm{Cl}_{2}$ from the surface of the sensors.

Fig. 9(b) shows the resistance variation in $S_{1}$ and $S_{2}$ sensors as a function of time for different concentrations of $\mathrm{Cl}_{2}$ (40$2000 \mathrm{ppb}$ ) at $150^{\circ} \mathrm{C}$. Upon exposure to $\mathrm{Cl}_{2}$, the sensor resistance decreases and it becomes saturated after some time; after purging with air, it again starts approaching its initial baseline value, indicating good reversibility. Fig. 9(c) demonstrates the response behaviour of $S_{1}$ and $S_{2}$ sensors to $40-2000 \mathrm{ppb}$ concentrations of $\mathrm{Cl}_{2}$. The response value of the sensors increased with increasing the concentration of $\mathrm{Cl}_{2}$. The responses of $\mathrm{S}_{1}$ and $\mathrm{S}_{2}$ sensors were found to lie in the range of $\sim 18-82 \%$ and $\sim 8-72 \%$, respectively. It is worth mentioning that the response of $\mathrm{F}_{16} \mathrm{MPc} / \mathrm{SWCNTs}-\mathrm{COOH}$ hybrids towards chlorine is greater than that of $\mathrm{F}_{16} \mathrm{MPc} / \mathrm{MWCNTs}-\mathrm{COOH}$ hybrids. ${ }^{28,29}$ Further, due to certain superior features of SWCNTs such as smaller size, stronger inter-tube attraction and larger specific surface area compared to the MWCNTs, the gas sensing parameters of the SWCNTs-based sensors are enhanced. The response of SWCNTs hybrids decreases in the order $\mathrm{F}_{16} \mathrm{CoPc}>$ $\mathrm{F}_{16} \mathrm{ZnPc}>\mathrm{F}_{16} \mathrm{CuPc},{ }^{28}$ which has been clarified in terms of the central ion size; i.e., the larger ionic radius and especially the interaction effects between $\mathrm{Cl}_{2}$ and different central ions. It was found that the interactions increase with the corresponding increase in the atomic size of the atoms/ions for a given
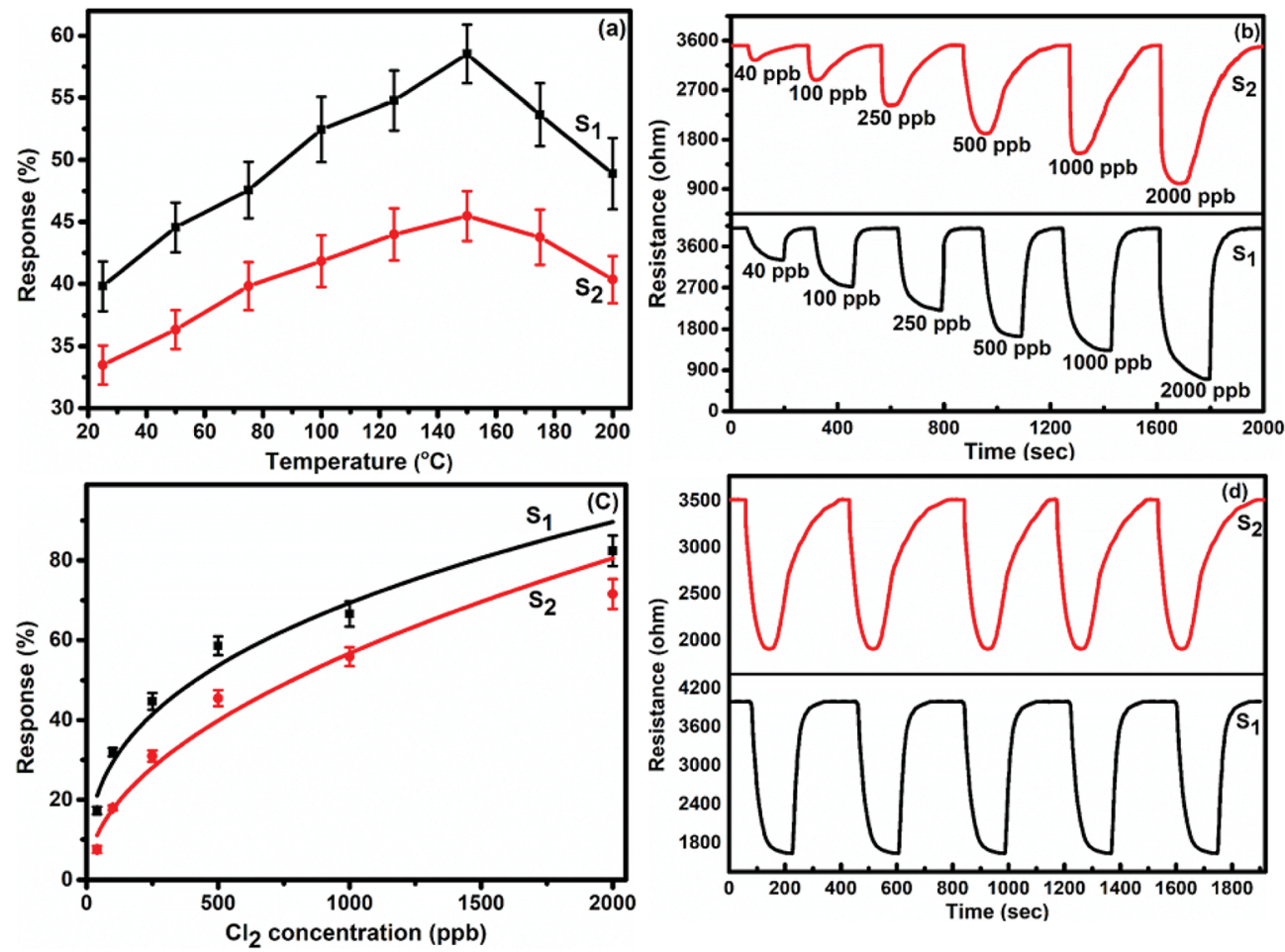

Fig. 9 (a) The response of $\mathrm{S}_{1}$ and $\mathrm{S}_{2}$ sensors as a function of temperature to $500 \mathrm{ppb}$ of $\mathrm{Cl}_{2}$. (b) Response curves of $\mathrm{S}_{1}$ and $\mathrm{S}_{2}$ sensors for different doses of $\mathrm{Cl}_{2}$ at $150^{\circ} \mathrm{C}$. (c) Variation in the response of $\mathrm{S}_{1}$ and $\mathrm{S}_{2}$ sensors with $\mathrm{Cl}_{2}$ concentration (experimental curve (dotted lines) and the fitting curve (solid lines)). (d) Reproducibility of the response curve of the $\mathrm{S}_{1}$ and $\mathrm{S}_{2}$ sensor to $500 \mathrm{ppb}$ of $\mathrm{Cl}_{2}$ at $150{ }^{\circ} \mathrm{C}$. (The standard error bars indicate the response variations after testing three sensor devices for three times). 


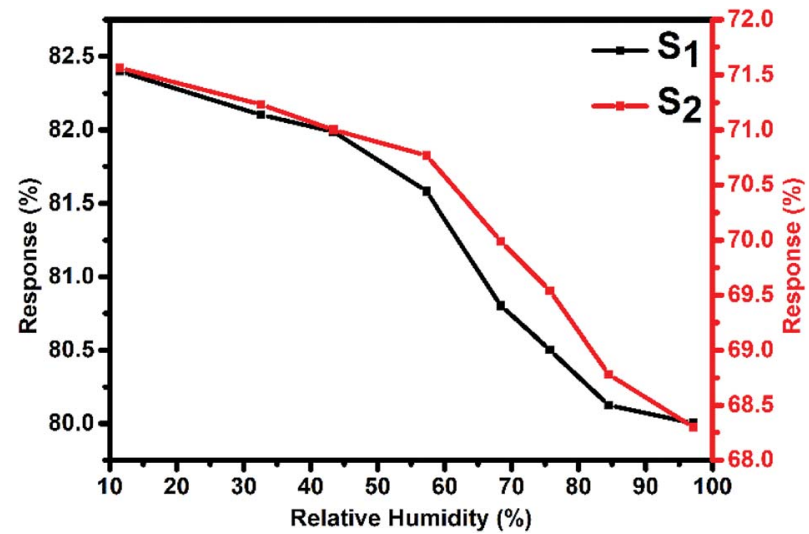

Fig. 10 Variation in the $\mathrm{Cl}_{2}$ response of $\mathrm{S}_{1}$ and $\mathrm{S}_{2}$ sensors with humidity for $2 \mathrm{ppm}$ of $\mathrm{Cl}_{2}$ at room temperature.

separation distance because larger atoms are more easily polarizable and provide more electrons to polarize, which results in strong van der Waals forces, indicating that the central metal size plays an important role in the sensitivity of $\mathrm{Cl}_{2}$. This is in agreement with charge transfer and the number
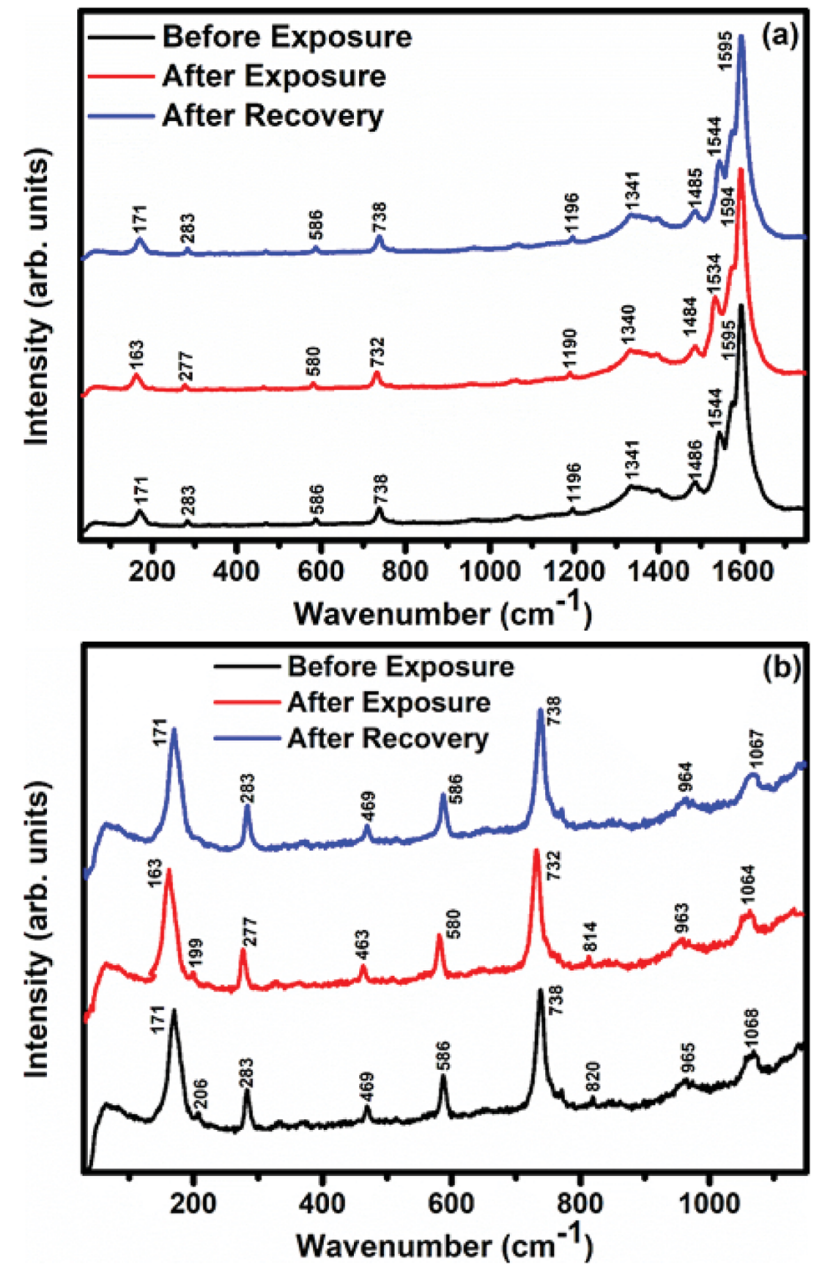

Fig. 11 Raman spectra of the $\mathrm{S}_{1}$ sensor recorded (a) before exposure (black curve), after exposure (red curve) to $25 \mathrm{ppm}$ of $\mathrm{Cl}_{2}$ and after full recovery (blue curve); (b) magnified view in the range $30-1300 \mathrm{~cm}^{-1}$. of Pc molecules adsorbed onto the SWCNTs wall, as estimated by TGA and $\mathrm{Cl}_{2}$ interactions with the sensor as observed in X-ray photoelectron and EIS studies discussed in Section 3.3.53 Fig. 9(d) shows the response curves of $S_{1}$ and $S_{2}$ sensors for successive exposures to $\mathrm{Cl}_{2}$. The sensors showed no significant changes in response and recovery characteristics after repeated gas exposure, demonstrating the reproducible and stable sensing characteristics of the sensors.

Fig. 10 represents the variation in the $\mathrm{Cl}_{2}$ response of $\mathrm{S}_{1}$ and $\mathrm{S}_{2}$ sensors with relative humidity (11-98\%) for $2000 \mathrm{ppb}$ of $\mathrm{Cl}_{2}$ at room temperature. It was observed that both sensors showed only small variations (2.4\% for $\mathrm{S}_{1}$ and $3.26 \%$ for $\mathrm{S}_{2}$ sensor) in their $\mathrm{Cl}_{2}$ response as the humidity level was varied from $11 \%$ to $98 \%$, indicating that humidity has a negligible effect on the $\mathrm{Cl}_{2}$ response of these sensors.

The response variation with the gas concentration was studied using eqn (2): $:^{54,55}$

$$
\frac{\Delta R}{R}=\alpha\left[\mathrm{Cl}_{2}\right]^{\beta}
$$

where $\alpha$ is the coefficient for the adsorption capacity and $\beta$ is the strength of adsorption, ${ }^{55}$ which are obtained by curve fitting of
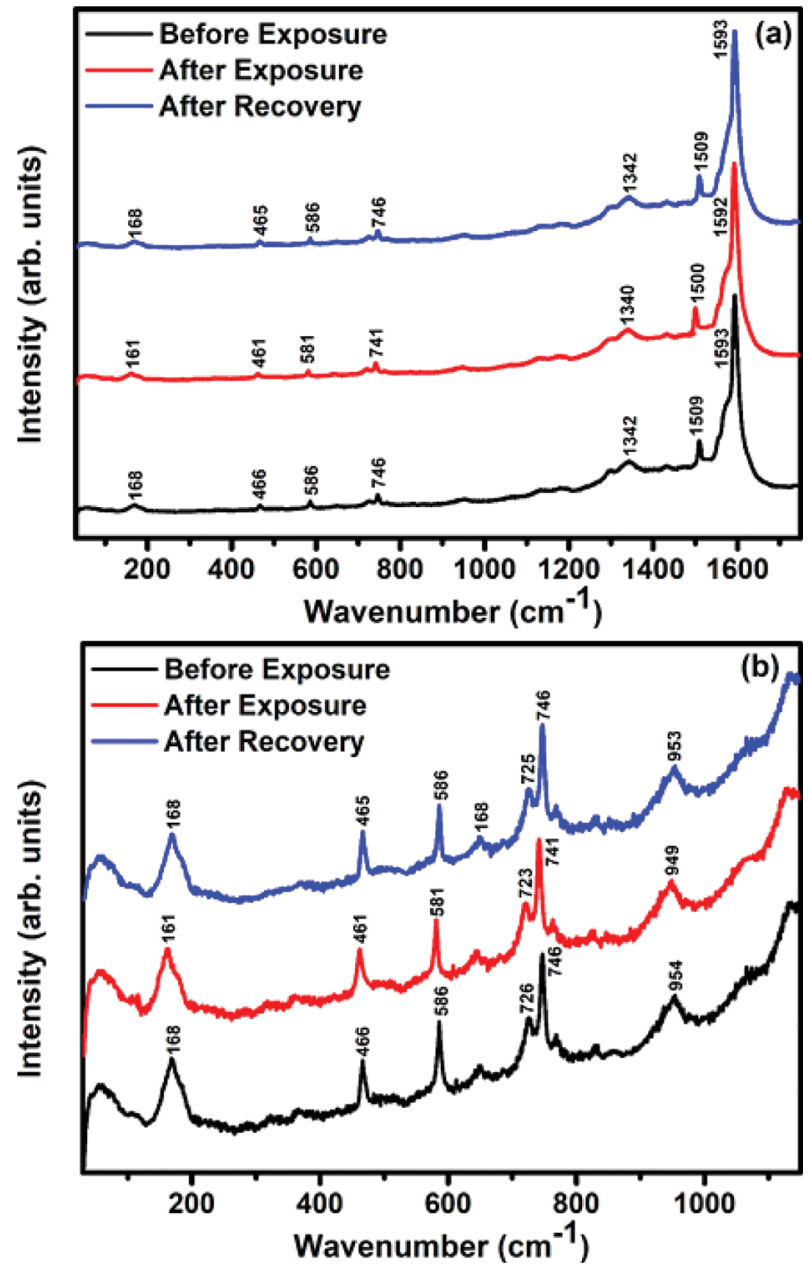

Fig. 12 Raman spectra of the $\mathrm{S}_{2}$ sensor recorded (a) before exposure (black curve); after exposure (red curve) to $25 \mathrm{ppm}$ of $\mathrm{Cl}_{2}$ and after full recovery (blue curve) (b) in the range $30-1300 \mathrm{~cm}^{-1}$ (magnified view). 
the response curve. It is interesting to note that a smaller value of $\beta$, lying between 0 and 1 for normal adsorption, signifies the greater heterogeneity of the sample. The values of $\alpha$ and $\beta$ were calculated to be 6.94 and 0.32 for $S_{1}$ and 2.62 and 0.43 for $S_{2}$ hybrids. A $\beta$ value less than one indicates the normal mode of adsorption on the heterogeneous surface of the sensor. ${ }^{54}$

In the above experimental study, the lowest detectable concentration is limited due to the experimental set up used. Nevertheless, the limit of detection (LOD) of the sensor was derived from the signal-to-noise ratio $(\mathrm{S} / \mathrm{N})$, which is defined as $\Delta R / \sigma$, where $\Delta R$ is the maximum resistance change with respect to $R_{\mathrm{a}}$ (baseline resistance) and $\sigma$ represents the root mean square (rms) noise of the baseline in air. ${ }^{56}$

The LOD was calculated by using the eqn (3): ${ }^{57}$

$$
\mathrm{LOD}=\frac{3 \times \text { concentration }}{\frac{\mathrm{S}}{\mathrm{N}}}
$$

The signal-to-noise ratios of sensors $S_{1}$ and $S_{2}$ are 3000 and 2400 , respectively, with the corresponding detection limits of $0.04 \mathrm{ppb}$ and $0.05 \mathrm{ppb}$, respectively. Thus, the higher sensitivity, reversibility and reproducibility of the $\mathrm{F}_{16} \mathrm{MPc} / \mathrm{SWCNT}$ hybrid sensor in comparison to other CNTs-based $\mathrm{Cl}_{2}$ sensors reported in literature ${ }^{\mathbf{1}, 58}$ make these sensors favourable candidates for ppb level $\mathrm{Cl}_{2}$ detection.

\subsection{Gas sensing mechanism}

Raman, XPS and impedance spectroscopic measurements of $S_{1}$ and $S_{2}$ hybrid sensors have been performed both in air and after purging in $\mathrm{Cl}_{2}$ in order to explore the sensing mechanism of the sensors. On exposure of the $\mathrm{S}_{1}$ sensor to $\mathrm{Cl}_{2}$, the Raman peak (Fig. 11) corresponding to the cobalt-nitrogen bond ${ }^{59}\left(171 \mathrm{~cm}^{-1}\right)$ is shifted by $8 \mathrm{~cm}^{-1}$ and macro-cyclic vibration ${ }^{60}$ peaks $(283,586$, $738,820,1196 \mathrm{~cm}^{-1}$ ) are shifted by $6 \mathrm{~cm}^{-1}$, whereas D and G bands corresponding to SWCNTs-COOH (1341 and $1595 \mathrm{~cm}^{-1}$ ) are shifted by $1 \mathrm{~cm}^{-1} \cdot{ }^{38}$ In contrast, in the Raman spectra (Fig. 12) of sensor $\mathrm{S}_{2}$, the peak corresponding to the zinc-nitrogen bond ${ }^{59}$ $\left(168 \mathrm{~cm}^{-1}\right)$ is shifted by $7 \mathrm{~cm}^{-1}$ and macro-cyclic vibration ${ }^{60}$ peaks $\left(119,466,586,746 \mathrm{~cm}^{-1}\right)$ are shifted by $5 \mathrm{~cm}^{-1}$, whereas D and $\mathrm{G}$ bands corresponding to SWCNTs-COOH (1342 and $1593 \mathrm{~cm}^{-1}$ ) are shifted by 2 and $1 \mathrm{~cm}^{-1}$, respectively. ${ }^{38}$ The major shift of $10 \mathrm{~cm}^{-1}$ in $\mathrm{S}_{1}$ and $9 \mathrm{~cm}^{-1}$ in $\mathrm{S}_{2}\left(1544 \mathrm{~cm}^{-1}\right.$ and $1509 \mathrm{~cm}^{-1}$ ) corresponds to the displacement of the $\mathrm{C}-\mathrm{N}-\mathrm{C}$ bridge bond, closely linked to the cobalt and zinc ions of the phthalocyanine molecule. ${ }^{43}$ The higher shift in the $\mathrm{S}_{1}$ hybrid as compared to the $\mathrm{S}_{2}$ hybrid indicates the predominant interaction of $\mathrm{Cl}_{2}$ with the cobalt ions of the hybrid sensor. The Raman spectra of the



Fig. 13 XPS spectra of the $\mathrm{S}_{1}$ sensor recorded before and after exposure to $25 \mathrm{ppm}$ of $\mathrm{Cl}_{2}$. 
hybrid sensors recorded after purging $\mathrm{Cl}_{2}$ showed identical peaks to those of fresh samples, which reflects the excellent reversibility of these sensors.

The interactions between $\mathrm{Cl}_{2}$ and the $\mathrm{S}_{1} / \mathrm{S}_{2}$ hybrid sensors were further confirmed by observing the shifts in binding energy in the XPS spectra of unexposed and $\mathrm{Cl}_{2}$ exposed samples. The XPS spectrum (Fig. 13) of the fresh $\mathrm{S}_{1}$ hybrid shows characteristic peaks at 284.7, 532.1, 399.0, 686.9, 780.0, $795.3 \mathrm{eV}$ corresponding to C-1s, O-1s, N-1s, F-1s, Co- $2 \mathrm{p}_{3 / 2}$ and Co- $2 \mathrm{p}_{1 / 2}$ levels, respectively. ${ }^{40}$ Once the sample was exposed to $\mathrm{Cl}_{2}$, there was a peak shift of $0.2 \mathrm{eV}$ in the spectrum of the core level C-1s, a shift of $0.1 \mathrm{eV}$ in the spectrum of $\mathrm{O}-1 \mathrm{~s}$ and $\mathrm{F}-1 \mathrm{~s}$, a shift of $0.3 \mathrm{eV}$ in the spectrum of $\mathrm{N}-1 \mathrm{~s}$ and a prominent peak shift of $0.8 \mathrm{eV}$ in the core level spectrum of Co-2p. In contrast, the XPS spectrum (Fig. 14) of the fresh $\mathrm{S}_{2}$ hybrid showed characteristic peaks at 284.8, 532.6, 399.0, 687.1, 1019.6, $1042.6 \mathrm{eV}$ corresponding to C-1s, O-1s, N-1s, F-1s, Zn$2 \mathrm{p}_{3 / 2}$ and $\mathrm{Zn}-2 \mathrm{p}_{1 / 2}$ levels ${ }^{24}$ and after $\mathrm{Cl}_{2}$ exposure, there was a peak shift of $0.2 \mathrm{eV}$ in spectrum of core level F-1s, a shift of $0.1 \mathrm{eV}$ in the spectra of $\mathrm{C}-1 \mathrm{~s}$ and $\mathrm{O}-1 \mathrm{~s}$, a shift of $0.3 \mathrm{eV}$ in the spectrum of $\mathrm{N}-1 \mathrm{~s}$ and a prominent peak shift of $0.7 \mathrm{eV}$ in the core level spectrum of $\mathrm{Zn}-2 \mathrm{p}$. The prominent shift of $0.8 \mathrm{eV}$ towards the higher $\mathrm{BE}$ side in the Co-2p core level in the $\mathrm{S}_{1}$ hybrid, a shift of $0.7 \mathrm{eV}$ towards the higher BE side in the $\mathrm{Zn}-2 \mathrm{p}$ core level in the $\mathrm{S}_{2}$ hybrid and a shift of $0.5 \mathrm{eV}$ towards the higher $\mathrm{BE}$ side in $\mathrm{Cu}-2 \mathrm{p}^{28}$ confirm that charge transfer interactions occur upon adsorption of strong electron acceptor $\mathrm{Cl}_{2}$ molecules to the hybrid, leading to a decrease in electron density due to the transfer of electrons from the hybrid to $\mathrm{Cl}_{2} \cdot{ }^{29,61}$ Thus, the analysis of the Raman and XPS spectroscopic observations is concomitant with the higher sensing response of the $S_{1}$ hybrid because greater charge transfer takes place between $\mathrm{Cl}_{2}$ and the $\mathrm{S}_{1}$ hybrid through the central metal ion with the adsorption of $\mathrm{Cl}_{2}$. Nevertheless, charge can favourably travel from CNTs to $\mathrm{F}_{16} \mathrm{MPcs}$, which leads to an increase in the hole concentration in CNTs and results in the fast variation in resistance as observed in Fig. 9(b). ${ }^{61,62}$ It is worth mentioning that there was no shifting of peak position in the XPS spectrum after recovery, and the absence of any chlorine signal confirms that the sensing process is highly reproducible.

The interaction between the $\mathrm{F}_{16} \mathrm{MPc} / \mathrm{SWCNTs}-\mathrm{COOH}$ sensor and $\mathrm{Cl}_{2}$ has also been further studied using impedance spectroscopy tools, providing information about $\mathrm{F}_{16} \mathrm{MPc} / \mathrm{SWCNTs-}$ $\mathrm{COOH}$ grains and the respective grain boundaries in accordance with morphological studies. Fig. 15(a and b) shows the impedance spectra of the $\mathrm{F}_{16} \mathrm{MPc} / \mathrm{SWCNTs}-\mathrm{COOH}$ sensor, obtained in air and under exposure to $500 \mathrm{ppb}$ of $\mathrm{Cl}_{2}$, i.e., the ColeCole plot. ${ }^{53,63}$ With an equivalent circuit (in the inset in Fig. 15)

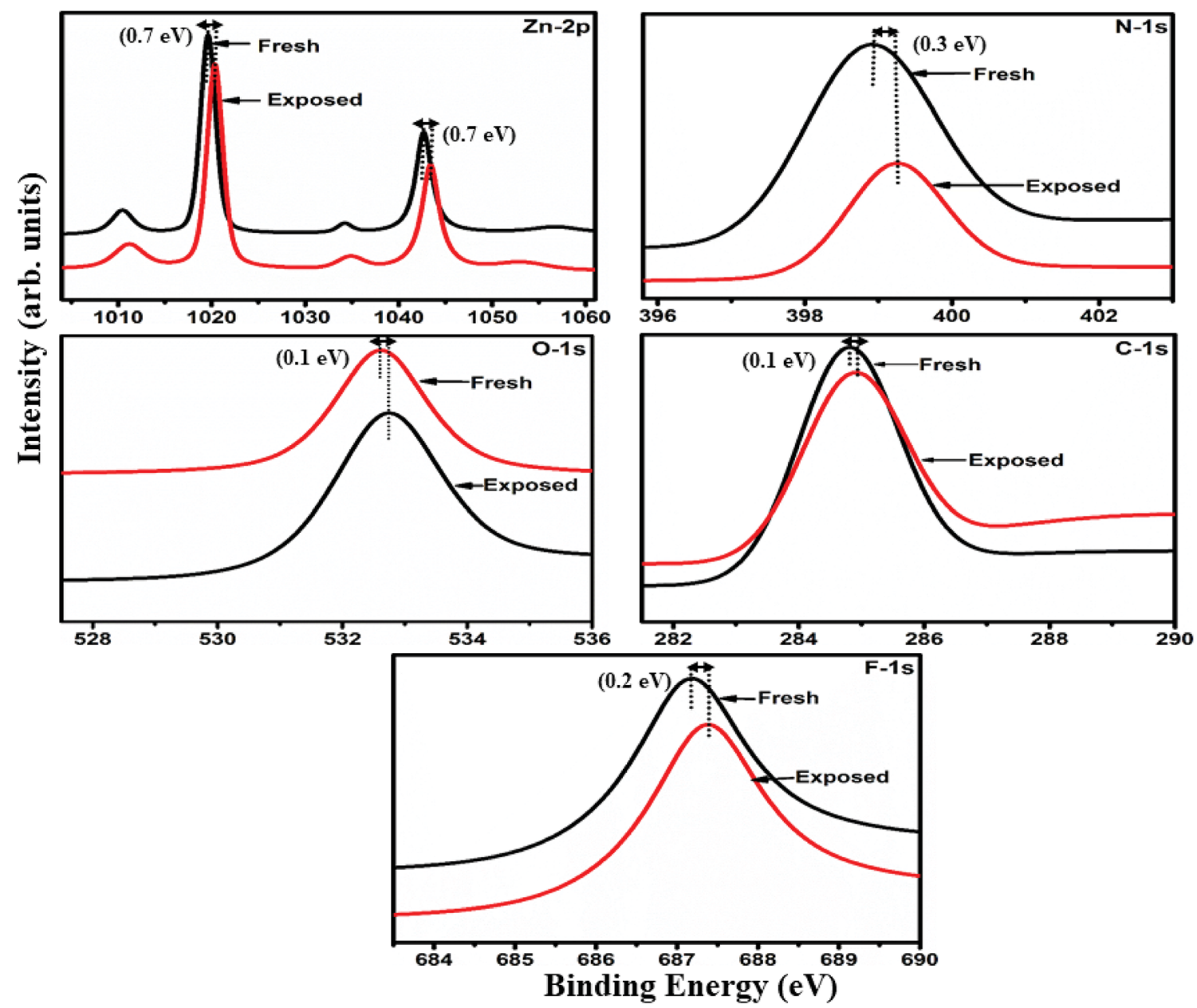

Fig. 14 XPS spectra of the $\mathrm{S}_{2}$ sensor recorded before and after exposure to $25 \mathrm{ppm}$ of $\mathrm{Cl}_{2}$. 

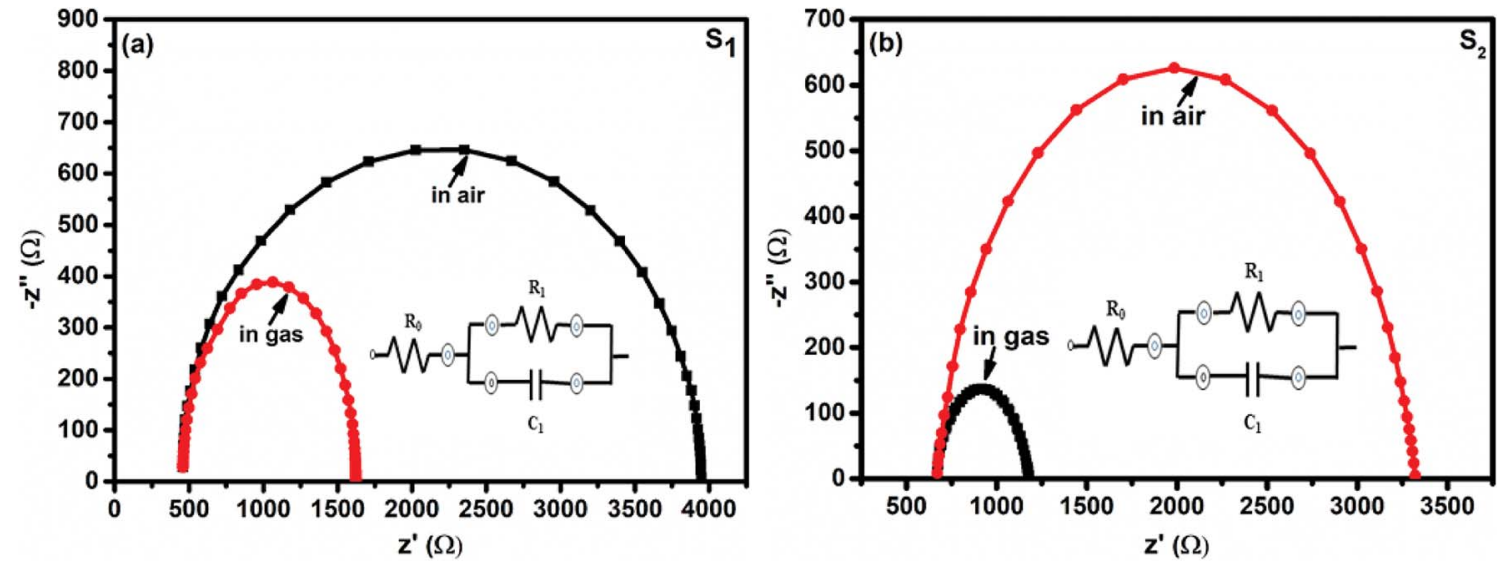

Fig. 15 Impedance spectra of fresh and $\mathrm{Cl}_{2}$ exposed $\mathrm{S}_{1}$ and $\mathrm{S}_{2}$ sensors (the insets show the equivalent circuits used for the analysis of data obtained from the $S_{1}$ and $S_{2}$ sensors).

Table 1 Impedance parameters obtained for $S_{1}$ and $S_{2}$ sensors by fitting experimental data to the equivalent circuit

\begin{tabular}{lllll}
\hline & & \multicolumn{2}{l}{ Parameters } \\
\cline { 3 - 4 } Sensors & Conditions & $R_{0}(\Omega)$ & $R_{1}(\Omega)$ & $C_{1}(\mathrm{nF})$ \\
\hline $\mathrm{S}_{1}$ & Unexposed & 458 & 3488 & 2 \\
& Exposed to $500 \mathrm{ppb} \mathrm{Cl}_{2}$ & 458 & 1164 & 5 \\
$\mathrm{~S}_{2}$ & Unexposed & 671 & 2649 & 3 \\
& Exposed to $500 \mathrm{ppb} \mathrm{Cl}_{2}$ & 671 & 507 & 11
\end{tabular}

consisting of the RC network in series with a resistor $R_{0}$, a single semi-circle was observed before and after exposure to $\mathrm{Cl}_{2}$. The intercept of the arc at high frequency with the real axis gives the grain resistance $\left(R_{0}\right)$. The resistance across the grain boundary $\left(R_{1}\right)$ was found from the diameter of the arc in Fig. 15, whereas the capacitance across the grain boundary $\left(C_{1}\right)$ was estimated from the relation.

$$
\omega_{\max } R_{1} C_{1}=1
$$

where $\omega_{\max }$ is the frequency corresponding to the top of the arc. $^{53}$ The equivalent circuit ${ }^{63}$ can be described as follows:

$$
Z=Z^{\prime}+j Z^{\prime \prime}
$$

where $Z^{\prime}=R_{0}+\left[R_{1} /\left(1+\omega R_{1} C_{1}\right)^{2}\right]$ and

$$
Z^{\prime \prime}=\left[\omega R_{1}^{2} C_{1} /\left(1+\omega R_{1} C_{1}\right)^{2}\right] .
$$

Interestingly, the parameter $R_{0}$ remained the same in $\mathrm{S}_{1}$ and $\mathrm{S}_{2}$ sensors in air and on exposure to $\mathrm{Cl}_{2}$, but $R_{1}$ decreased and $C_{1}$ increased in the presence of $\mathrm{Cl}_{2}$. This result is also supported by the fact that $R_{1}$ changes across the grain boundary in the order of $\mathrm{S}_{1}>\mathrm{S}_{2}>\mathrm{H}_{1}$ (ref. 28) for hybrid sensors, indicating that incoming $\mathrm{Cl}_{2}$ molecules were adsorbed onto the outer surfaces of the grains and resulted in increased hole conductivity because of the charge transfer between phthalocyanines and CNTs, as explained in XPS investigations (Table 1). ${ }^{\mathbf{2 8 , 5 3}}$

\section{Conclusions}

We have fabricated $\mathrm{F}_{16} \mathrm{CoPc} / \mathrm{SWCNTs}-\mathrm{COOH}$ and $\mathrm{F}_{16} \mathrm{ZnPc} /$ SWCNTs-COOH hybrid sensors using the solution assembly route, through $\pi-\pi$ stacking interactions between $\mathrm{F}_{16} \mathrm{MPc}$ and SWCNTs-COOH for chlorine sensing applications. The results demonstrate that the $\mathrm{F}_{16} \mathrm{CoPc} / \mathrm{SWCNTs}-\mathrm{COOH}$ sensor exhibits high sensitivity ( $\sim 82 \%$ for $2 \mathrm{ppm}$ with LOD of $0.04 \mathrm{ppb}$ ), excellent reproducibility and selectivity towards chlorine with response decreasing in the order of $\mathrm{Co}>\mathrm{Zn}>\mathrm{Cu}$, indicating that the central metal ions play an important role in the sensitivity of $\mathrm{Cl}_{2}$, and this is in good agreement with the central ion size: the larger the ionic radius, the greater the charge transfer and $\mathrm{Cl}_{2}$ interaction with the sensor as observed from $\mathrm{X}$ ray photoelectron, Raman and electrochemical impedance spectroscopic studies. Such effectiveness of the sensor originates from the synergetic interaction between $\mathrm{F}_{16} \mathrm{MPc}$ and SWCNTs-COOH. Strong response and good selectivity underline the significant potential of these hybrid materials in designing a new low-cost $\mathrm{Cl}_{2}$ sensor.

\section{Conflicts of interest}

There are no conflicts to declare.

\section{Acknowledgements}

The authors gratefully acknowledge Council of Scientific and Industrial Research (CSIR), New Delhi, India for providing financial assistance to accomplish this research work.

\section{Notes and references}

1 J. Li, Y. Lu and M. Meyyappan, IEEE Sens. J., 2006, 6, 10471051.

2 A. K. Saroha, J. Chem. Health Saf., 2006, 13, 5-11.

3 J.-W. Kim, Y. Porte, K. Y. Ko, H. Kim and J.-M. Myoung, ACS Appl. Mater. Interfaces, 2017, 9, 32876-32886. 
4 A. Katoch, Z. U. Abideen, H. W. Kim and S. S. Kim, ACS Appl. Mater. Interfaces, 2016, 8, 2486-2494.

5 M. Sturaro, E. Della Gaspera, N. Michieli, C. Cantalini, S. M. Emamjomeh, M. Guglielmi and A. Martucci, ACS Appl. Mater. Interfaces, 2016, 8, 30440-30448.

6 N. Wu, C. Wang, B. R. Bunes, Y. Zhang, P. M. Slattum, X. Yang and L. Zang, ACS Appl. Mater. Interfaces, 2016, 8, 12360-12368.

7 K. Potje-Kamloth, Chem. Rev., 2008, 108, 367-399.

8 R. K. Paul, S. Badhulika, N. M. Saucedo and A. Mulchandani, Anal. Chem., 2012, 84, 8171-8178.

9 Z. Zanolli, R. Leghrib, A. Felten, J.-J. Pireaux, E. Llobet and J.-C. Charlier, ACS Nano, 2011, 5, 4592-4599.

10 C. Wang, L. Yin, L. Zhang, D. Xiang and R. Gao, Sensors, 2010, 10(3), 2088-2106.

11 T. Van Dang, N. Duc Hoa, N. Van Duy and N. Van Hieu, ACS Appl. Mater. Interfaces, 2016, 8, 4828-4837.

12 L. Huang, Z. Wang, X. Zhu and L. Chi, Nanoscale Horiz., 2016, 1, 383-393.

13 C. D. Natale, E. Martinelli, G. Magna, F. Mandoj, D. Monti, S. Nardis, M. Stefanelli and R. Paolesse, J. Porphyrins Phthalocyanines, 2017, 21, 769-781.

14 J. Li, Y. Lu, Q. Ye, M. Cinke, J. Han and M. Meyyappan, Nano Lett., 2003, 3, 929-933.

15 S. Deng, V. Tjoa, H. M. Fan, H. R. Tan, D. C. Sayle, M. Olivo, S. Mhaisalkar, J. Wei and C. H. Sow, J. Am. Chem. Soc., 2012, 134, 4905-4917.

16 T.-C. Lin and B.-R. Huang, Sens. Actuators, B, 2012, 162, 108113.

17 V. M. Aroutiounian, A. Z. Adamyan, E. A. Khachaturyan, Z. N. Adamyan, K. Hernadi, Z. Pallai, Z. Nemeth, L. Forro, A. Magrez and E. Horvath, Sens. Actuators, B, 2013, 177, 308-315.

18 A. K. Sharma, R. Saini, R. Singh, A. Mahajan, R. K. Bedi and D. K. Aswal, AIP Conf. Proc., 2014, 1591, 671-673.

19 B. Wang, Y. Wu, X. Wang, Z. Chen and C. He, Sens. Actuators, $B, 2014,190,157-164$.

20 X. Liang, Z. Chen, H. Wu, L. Guo, C. He, B. Wang and Y. Wu, Carbon, 2014, 80, 268-278.

21 M. Pișkin, N. Can, Z. Odabaș and A. Altındal, J. Porphyrins Phthalocyanines, 2018, 22, 189-197.

22 A. Yazıcı, N. Ünüș, A. Altındal, B. Salih and Ö. Bekaroğlu, Dalton Trans., 2012, 41, 3773-3779.

23 A. Kumar, A. Singh, A. K. Debnath, S. Samanta, D. K. Aswal, S. K. Gupta and J. V. Yakhmi, Talanta, 2010, 82, 1485-1489.

24 R. Saini, A. Mahajan, R. K. Bedi, D. K. Aswal and A. K. Debnath, Sens. Actuators, B, 2014, 198, 164-172.

25 R. Saini, A. Mahajan, R. K. Bedi, D. K. Aswal and A. K. Debnath, Sens. Actuators, B, 2014, 203, 17-24.

26 R. Olivé-Monllau, A. Pereira, J. Bartrolí, M. Baeza and F. Céspedes, Talanta, 2010, 81, 1593-1598.

27 B. Wang, X. Zhou, Y. Wu, Z. Chen and C. He, Sens. Actuators, B, 2012, 171-172, 398-404.

28 A. K. Sharma, A. Mahajan, R. Saini, R. K. Bedi, S. Kumar, A. K. Debnath and D. K. Aswal, Sens. Actuators, B, 2018, 255, 87-99.
29 A. K. Sharma, A. Mahajan, R. K. Bedi, S. Kumar, A. K. Debnath and D. K. Aswal, Appl. Surf. Sci., 2018, 427, 202-209.

30 A. K. Sharma, A. Mahajan, R. K. Bedi, S. Kumar, A. K. Debnath and D. K. Aswal, $R S C A d v$., 2017, 7, 4967549683.

31 E. N. Kaya, S. Tuncel, T. V. Basova, H. Banimuslem, A. Hassan, A. G. Gürek, V. Ahsen and M. Durmuş, Sens. Actuators, B, 2014, 199, 277-283.

32 H. Jiang, J. Ye, P. Hu, F. Wei, K. Du, N. Wang, T. Ba, S. Feng and C. Kloc, Sci. Rep., 2014, 4, 7573.

33 P. A. Pandey, L. A. Rochford, D. S. Keeble, J. P. Rourke, T. S. Jones, R. Beanland and N. R. Wilson, Chem. Mater., 2012, 24, 1365-1370.

34 D. G. de Oteyza, A. El-Sayed, J. M. Garcia-Lastra, E. Goiri, T. N. Krauss, A. Turak, E. Barrena, H. Dosch, J. Zegenhagen, A. Rubio, Y. Wakayama and J. E. Ortega, J. Chem. Phys., 2010, 133, 214703.

35 J. Liu, A. G. Rinzler, H. Dai, J. H. Hafner, R. K. Bradley, P. J. Boul, A. Lu, T. Iverson, K. Shelimov, C. B. Huffman, F. Rodriguez-Macias, Y.-S. Shon, T. R. Lee, D. T. Colbert and R. E. Smalley, Science, 1998, 280, 1253-1256.

36 Z. Zhao, Z. Yang, Y. Hu, J. Li and X. Fan, Appl. Surf. Sci., 2013, 276, 476-481.

37 B. Chitara, D. J. Late, S. B. Krupanidhi and C. N. R. Rao, Solid State Commun., 2010, 150, 2053-2056.

38 P. C. Eklund, J. M. Holden and R. A. Jishi, Carbon, 1995, 33, 959-972.

39 M. L. de la Chapelle, S. Lefrant, C. Journet, W. Maser, P. Bernier and A. Loiseau, Carbon, 1998, 36, 705-708.

40 Y. Wang, N. Hu, Z. Zhou, D. Xu, Z. Wang, Z. Yang, H. Wei, E. S.-W. Kong and Y. Zhang, J. Mater. Chem., 2011, 21, 3779-3787.

41 C. Jennings, R. Aroca, A.-M. Hor and R. O. Loutfy, J. Raman Spectrosc., 1984, 15, 34-37.

42 S. Tuncel, E. N. Kaya, M. Durmus, T. Basova, A. G. Gurek, V. Ahsen, H. Banimuslem and A. Hassan, Dalton Trans., 2014, 43, 4689-4699.

43 M. Szybowicz and J. Makowiecki, J. Mater. Sci., 2012, 47, 1522-1530.

44 Y. Zhang, J. Zhang, H. Son, J. Kong and Z. Liu, J. Am. Chem. Soc., 2005, 127, 17156-17157.

45 E. N. Kaya, T. Basova, M. Polyakov, M. Durmuş, B. Kadem and A. Hassan, RSC Adv., 2015, 5, 91855-91862.

46 J. Zhang, H. Zou, Q. Qing, Y. Yang, Q. Li, Z. Liu, X. Guo and Z. Du, J. Phys. Chem. B, 2003, 107, 3712-3718.

47 S. Harbeck, Ö. F. Emirik, I. Gürol, A. G. Gürek, Z. Z. Öztürk and V. Ahsen, Sens. Actuators, B, 2013, 176, 838-849.

48 S. Singh, S. K. Tripathi and G. S. S. Saini, Mater. Chem. Phys., 2008, 112, 793-797.

49 A. Ma, J. Lu, S. Yang and K. M. Ng, J. Cluster Sci., 2006, 17, 599-608.

50 T. Mugadza and T. Nyokong, Electrochim. Acta, 2009, 54, 6347-6353.

51 H. Zhao, Y. Zhang, B. Zhao, Y. Chang and Z. Li, Environ. Sci. Technol., 2012, 46, 5198-5204. 
52 B.-P. Jiang, L.-F. Hu, D.-J. Wang, S.-C. Ji, X.-C. Shen and H. Liang, J. Mater. Chem. B, 2014, 2, 7141-7148.

$53 \mathrm{~N}$. H. Al-Hardan, M. J. Abdullah and A. A. Aziz, Int. J. Hydrogen Energy, 2010, 35, 4428-4434.

54 D. Kumar, P. Chaturvedi, P. Saho, P. Jha, A. Chouksey, M. Lal, J. S. B. S. Rawat, R. P. Tandon and P. K. Chaudhury, Sens. Actuators, B, 2017, 240, 1134-1140.

55 I. Sayago, H. Santos, M. C. Horrillo, M. Aleixandre, M. J. Fernández, E. Terrado, I. Tacchini, R. Aroz, W. K. Maser, A. M. Benito, M. T. Martínez, J. Gutiérrez and E. Muñoz, Talanta, 2008, 77, 758-764.

56 F. Rigoni, S. Tognolini, P. Borghetti, G. Drera, S. Pagliara, A. Goldoni and L. Sangaletti, Analyst, 2013, 138, 7392-7399. 57 G. Chen, T. M. Paronyan, E. M. Pigos and A. R. Harutyunyan, Sci. Rep., 2012, 2, 343.
58 A. Gohier, J. Chancolon, P. Chenevier, D. Porterat, M. MayneL'Hermite and C. Reynaud, Nanotechnology, 2011, 22, 105501.

59 G. S. S. Saini, S. Sukhwinder, K. Sarvpreet, K. Ranjan, S. Vasant and S. K. Tripathi, J. Phys.: Condens. Matter, 2009, 21, 225006.

60 L. L. Gladkov, V. V. Gromak and V. K. Konstantinova, J. Appl. Spectrosc., 2007, 74, 328-332.

61 R. A. Hatton, N. P. Blanchard, V. Stolojan, A. J. Miller and S. R. P. Silva, Langmuir, 2007, 23, 6424-6430.

62 A. L. Verma, S. Saxena, G. S. S. Saini, V. Gaur and V. K. Jain, Thin Solid Films, 2011, 519, 8144-8148.

63 A. T. Mane, S. T. Navale, S. Sen, D. K. Aswal, S. K. Gupta and V. B. Patil, Org. Electron., 2015, 16, 195-204. 